\title{
A standard for hilar and intrapulmonary lymph node dissection and pathological examination in early non-small cell lung cancer
}

\author{
Zhihua Zhu ${ }^{1 \#}$, Weijian Mei ${ }^{1 \#}$, Zhengbo Song" ${ }^{2 \#}$ Wenjie Jiao" ${ }^{3 \#}$, Qinghua Huang ${ }^{4 \#}$, Lianxin Zhu ${ }^{5,6 \#}$, \\ Chaolun $\mathrm{An}^{7}$, Jianguang Shi ${ }^{8}$, Wenxian Wang ${ }^{2}$, Guiping Yu', Pingli Sun ${ }^{10}$, Yinbin Zhang ${ }^{11}$, Jianfei Shen ${ }^{12}$, \\ Yong Song $^{13}$, Sebastien Gilbert ${ }^{14}$, Kurt Ruetzler ${ }^{15}$, Nestor R. Villamizar ${ }^{16}$, Chunwei Xu ${ }^{13}$, Jun Qian ${ }^{17}$, \\ Wang Yao ${ }^{18}$, Han Yang ${ }^{1}$; written on behalf of AME Lung Cancer Collaborative Group
}

${ }^{1}$ Department of Thoracic Surgery, Sun Yat-sen University Cancer Center, State Key Laboratory of Oncology in South China, Collaborative Innovation Center for Cancer Medicine, Guangzhou, China; ${ }^{2}$ Department of Medical Oncology, Cancer Hospital of University of Chinese Academy of Sciences, Zhejiang Cancer Hospital, Hangzhou, China; ${ }^{3}$ Department of Thoracic Surgery, Affiliated Hospital of Qingdao University, Qingdao, China; ${ }^{4}$ Department of Breast Surgery, Affiliated Tumor Hospital of Guangxi Medical University, Nanning, China; ${ }^{5}$ Medical College of Nanchang University, Nanchang, China; ${ }^{6}$ Department of Clinic Medicine, School of Queen Mary, Nanchang University, Nanchang, China; ${ }^{7}$ Department of Thoracic Surgery, Nantong Third People's Hospital Nantong University, Nantong, China; ${ }^{8}$ Department of Thoracic Surgery, Ningbo First Hospital of Zhejiang University, Ningbo, China; ' Department of Thoracic Surgery, Affiliated Jiangyin Hospital of Southeast University, Jiangyin, China; ${ }^{10}$ Department of Pathology, The Second Hospital of Jilin University, Changchun, China; ${ }^{11}$ Department of Thoracic Surgery, The Second Affiliated Hospital of Medical College, Xi'an Jiaotong University, Xi'an, China; ${ }^{12}$ Department of Thoracic Surgery, Taizhou Hospital of Zhejiang Province, Wenzhou Medical University, Taizhou, China; ${ }^{13}$ Department of Respiratory Medicine,, Affiliated Jinling Hospital, Medical School of Nanjing University, Nanjing, China; ${ }^{14}$ Division of Thoracic Surgery, Faculty of Medicine, University of Ottawa, Ottawa, ON, Canada; ${ }^{15}$ Departments of Outcomes Research and General Anesthesia, Anesthesiology Institute, Cleveland Clinic, Cleveland, OH, USA; ${ }^{16}$ Section of Thoracic Surgery, Department of Surgery, Miller School of Medicine, University of Miami, Miami, FL, USA; ${ }^{17}$ Department of Statistics, Southern Medical University, Guangzhou, China; ${ }^{18}$ Department of Interventional Oncology, The First Affiliated Hospital, Sun Yat-sen University, Guangzhou, China

Contributions: (I) Conception and design: W Yao, Z Zhu, H Yang; (II) Administrative support: Z Song, W Jiao, C Xu, Q Huang, C An, J Shi, G Yu, P Sun, Y Zhang, J Shen; (III) Provision of study materials or patients: Q Huang, C An, J Shi, G Yu, P Sun, Y Zhang, J Shen, Z Zhu; (IV) Collection and assembly of data: W Mei, L Zhu; (V) Data analysis and interpretation: J Qian, L Zhu; (VI) Manuscript writing: All authors; (VII) Final approval of manuscript: All authors.

"These authors contributed equally to this work.

Correspondence to: Chunwei Xu, MD, PhD. Department of Respiratory Medicine, Affiliated Jinling Hospital, Medical School of Nanjing University, 305 Zhongshan Road, Nanjing 210002, China. Email: xuchunweibbb@163.com; Jun Qian, PhD. Department of Statistics, Southern Medical University, 1023 Shatainan Road, Guangzhou 510515, China. Email: qianjun_gz@126.com; Dr. Wang Yao, MD. Department of Interventional Oncology, The First Affiliated Hospital, Sun Yat-sen University, 58 Zhongshan Second Road, Guangzhou 510060, China. Email: yaow7@mail.sysu.edu.cn; Dr. Han Yang, MD, PhD. Department of Thoracic Surgery, Sun Yat-sen University Cancer Center, State Key Laboratory of Oncology in South China, Collaborative Innovation Center for Cancer Medicine, 651 Dongfeng Road East, Guangzhou 510060, China. Email: yanghan@sysucc.org.cn.

Background: There is considerable variation in the staging of lymph nodes (LNs) as part of tumor, node, metastasis (TNM) staging of non-small cell lung cancer (NSCLC). A new dissection and pathological examination standard for hilar and intrapulmonary LNs needs to be established for patients with early-stage T1-3N0M0 NSCLC.

Methods: This study involved 3,002 patients with T1-3N0M0 NSCLC who underwent radical lobectomy or total pneumonectomy in the thoracic departments of 11 Chinese institutions between January 1999 and October 2013. The Cox model was applied for univariate and multivariate analyses in the examination of station 10, $11 \mathrm{LN}$ and station 12, 13, $14 \mathrm{LN}$. A hilar and intrapulmonary standard (HI standard) was then established based on univariate and multiple-factor analyses conducted using the Cox model.

Results: Among the 3,002 patients enrolled in the study, 2,609 underwent at least one examination of station 10, $11 \mathrm{LN}$ (A1), while 393 did not undergo examination of station 10, $11 \mathrm{LN}$ (A0). The A0 and A1 groups had 5 -year survival rates of $76 \%$ and $80 \%$, respectively $(\mathrm{P}=0.018)$. Further, 1,764 patients underwent 
at least one examination of station $12,13,14 \mathrm{LN}$ (B1), while 1,238 patients did not (B0). The B0 and B1 groups had 5 -year survival rates of $77 \%$ and $82 \%$, respectively $(\mathrm{P}=0.008)$. In total, 1,269 patients attained the HI standard (C1), and 1,733 did not (C0). The C0 and $\mathrm{C} 1$ groups had 5 -year survival rates of $77 \%$ and $83 \%$, respectively $(\mathrm{P}<0.001)$.

Conclusions: The HI standard can improve both the prognosis and survival rates of patients with T1-3N0M0 NSCLC. This will provide important guidance for pulmonary LN dissection and pathological examination in NSCLC cases.

Keywords: Non-small cell lung cancer (NSCLC); lymph node dissection (LN dissection); early stage; pathological examination standard

Submitted Oct 27, 2021. Accepted for publication Dec 23, 2021.

doi: $10.21037 /$ tlcr-21-959

View this article at: https://dx.doi.org/10.21037/tlcr-21-959

\section{Introduction}

Precise staging forms the foundation of effective treatment in non-small cell lung cancer (NSCLC) $(1,2)$. Among the various cancer staging systems, the tumor, node, metastasis (TNM) classification is widely considered optimal for differentiating the prognosis of patients with NSCLC (3). However, in TNM staging, there is considerable variation in the staging of lymph nodes (LNs), or $\mathrm{N}$ staging. Research has shown that for $\mathrm{N}$ staging, pathological staging is more accurate than clinical staging; however, pathological staging is dependent on intraoperative $\mathrm{LN}$ dissection and postoperative pathological verification (4).

International standards including those of the National Comprehensive Cancer Network (NCCN) (5), European Society of Thoracic Surgeons (ESTS) (6,7), Chinese Medical Association (CMA) (8), and American College of Surgeons Commission on Cancer (COC) (9) differ regarding the optimal number of examined LNs (ELNs). Samayoa et al.'s retrospective study revealed that the overall survival (OS) of patients with early NSCLC could be significantly improved with at least 10 ELNs (10), and our previous study arrived at the same conclusion (11). Therefore, a minimum of 10 ELNs served as the basis for the hilar and intrapulmonary LNs quantitative standard (HI standard) in the current study.

The location of ELNs can also influence the precision of pathologic LN (pN) staging (12-14). Multiple studies have reported that the precision of $\mathrm{pN}$ staging was significantly affected when LNs at the N1 station, especially intrapulmonary LNs, were not examined (15-17), which further impacted patients' prognosis (18-20). However, the current surgery recommendations only specify the sampling standard of mediastinal LNs, with no specific regulation for ELNs at N1; in particular, there is no acknowledged standard for the examination of intrapulmonary LNs. The NCCN guidelines recommend that $3 \mathrm{~N} 1 \mathrm{LN}$ s should be examined (5), whereas those of ESTS only mention the dissection of hilar LNs (6,7). The 2018 edition of the CMA clinical guidelines for lung cancer suggested at least 12 ELNs in the mediastinum and lung, but included no further regulation on N1 LNs (8). Similarly, the COC recommendations did not include the examination of $\mathrm{N} 1$ LNs (9). However, the Association of Directors of Anatomic and Surgical Pathology suggested that all pulmonary LNs should be dissected and examined (21). Based on these controversial recommendations, it therefore remains unclear, how many and which N1 LNs should be examined.

Therefore, the aim of this Chinese multicenter is to identify the optimal number and location of ELNs, and the association of ELNs on the prognosis of patients with T13NOM0 NSCLC. The study of LN location was separated into two sections: the first focused on station 10 and 11 LNs (the hilar/interlobar zone) and the second on station 12, 13, and 14 LNs (the peripheral zone) (22). Based on the above, we first established a standard for LN dissection and pathological examination (HI standard) in NSCLC, which recommends a minimum of 10 ELNs, including at least one $\mathrm{LN}$ from either station 10 or 11 and one $\mathrm{LN}$ each from station 12, 13, or 14, each. We present the following article in accordance with the STROBE reporting checklist (available at https://dx.doi.org/10.21037/tlcr-21-959). 


\section{Methods}

\section{Patients and etbics statement}

The data for this study was obtained from a Chinese multiinstitutional retrospective database. This included a registry of continuously collected data of patients with NSCLC who underwent surgical resection in the thoracic departments of 11 institutions in China (Sun Yat-sen University Cancer Center; Zhejiang Cancer Hospital; Affiliated Hospital of Qingdao University; Affiliated Tumor Hospital of Guangxi Medical University; Fujian Cancer Hospital, Fujian Medical University; The Second Affiliated Hospital of Medical College, Xi'an Jiaotong University; Taizhou First People's Hospital; Third People's Hospital of Nantong City; Ningbo First Hospital, Ningbo Hospital of Zhejiang University; Affiliated Jiangyin Hospital of Southeast University; the Second Hospital of Jilin University) between January 1999 and October 2013.

The study was conducted in accordance with the Declaration of Helsinki (as revised in 2013). Ethical approval was obtained from the institutional review board of Sun Yat-sen University Cancer Center (No. YB201811). Individual consent for this study was waived by the ethics committee. All patients were staged with reference to the $8^{\text {th }}$ edition of the TNM classification. LNs were either dissected during surgical resection or re-sampled by the surgeon following the operation. The final number of LNs was determined by the pathologist.

\section{Inclusion and exclusion criteria}

The inclusion criteria for patients in this study included: (I) diagnosed with NSCLC and histologically and pathologically staged as T1-3N0M0 according to the NCCN TNM classification; (II) underwent complete (R0) resection plus $\mathrm{LN}$ dissection or sampling with at least one LN that was harvested and examined; (III) followed up for a minimum of 5 years. The exclusion criteria were as follows: (I) patients with a history of synchronous or metachronous malignancy; (II) patients who had positive resection margins or who underwent palliative surgery including sublobectomy, segmentectomy, or wedge-shaped lobectomy; (III) patients who received chemotherapy, radiation, target therapy, or any other antitumor therapy before surgery; and (IV) patients who died within 30 days post-surgery.

\section{The standard definition}

HI standard: recommend at least 10 ELNs (11), including at least one station $10,11 \mathrm{LN}$ and one station 12,13 , $14 \mathrm{LN}$.

\section{Follow-up}

OS was the endpoint of this study. OS was calculated from the date of the operation until the patient's death or the end of the follow-up period. Follow-up was conducted by staff from the hospitals' follow-up sections or by trained medical staff via telephone. The final follow-up date was October 31, 2018. All patients were followed-up.

\section{Statistical analysis}

Categorical variables were presented as frequency (\%), and continuous variables as median [interquartile range (IQR)]. The Pearson's chi-square test was used for categorical variables to compare population characteristics, and the independent $t$-test (or Mann-Whitney U-test) was used for continuous variables. Survival was estimated using the Kaplan-Meier method, and any survival differences were evaluated by stratified log-rank test. Multivariable analyses using the Cox proportional-hazards model were performed to estimate the simultaneous effects of prognostic factors on survival. The Kaplan-Meier method and log-rank tests were used to estimate OS. SPSS software (version 24.0 SPSS Inc., Chicago, IL, USA) was used for all statistical analyses. A two-sided level of significance was applied, with a $\mathrm{P}$ value of less than 0.05 indicating statistical significance.

\section{Results}

\section{Baseline condition of the study participants}

A total of 3,002 patients were selected for this study (Figure 1 for the selection process), among whom 721 patients died $(24.0 \%)$, with the median follow-up being 65.9 months. Most patients were aged $<65$ years $(66.2 \%)$ and male (63.0\%). The majority of patients were staged as $\mathrm{T} 1$ or $\mathrm{T} 2$, with $\mathrm{T} 1, \mathrm{~T} 2$, and $\mathrm{T} 3$ cases accounting for $40.5 \%$, $48.5 \%$, and $11.1 \%$ of the study population, respectively. Comprising $66.1 \%$ of cases, adenocarcinoma (AC) was the main histological type of NSCLC in this study, while 


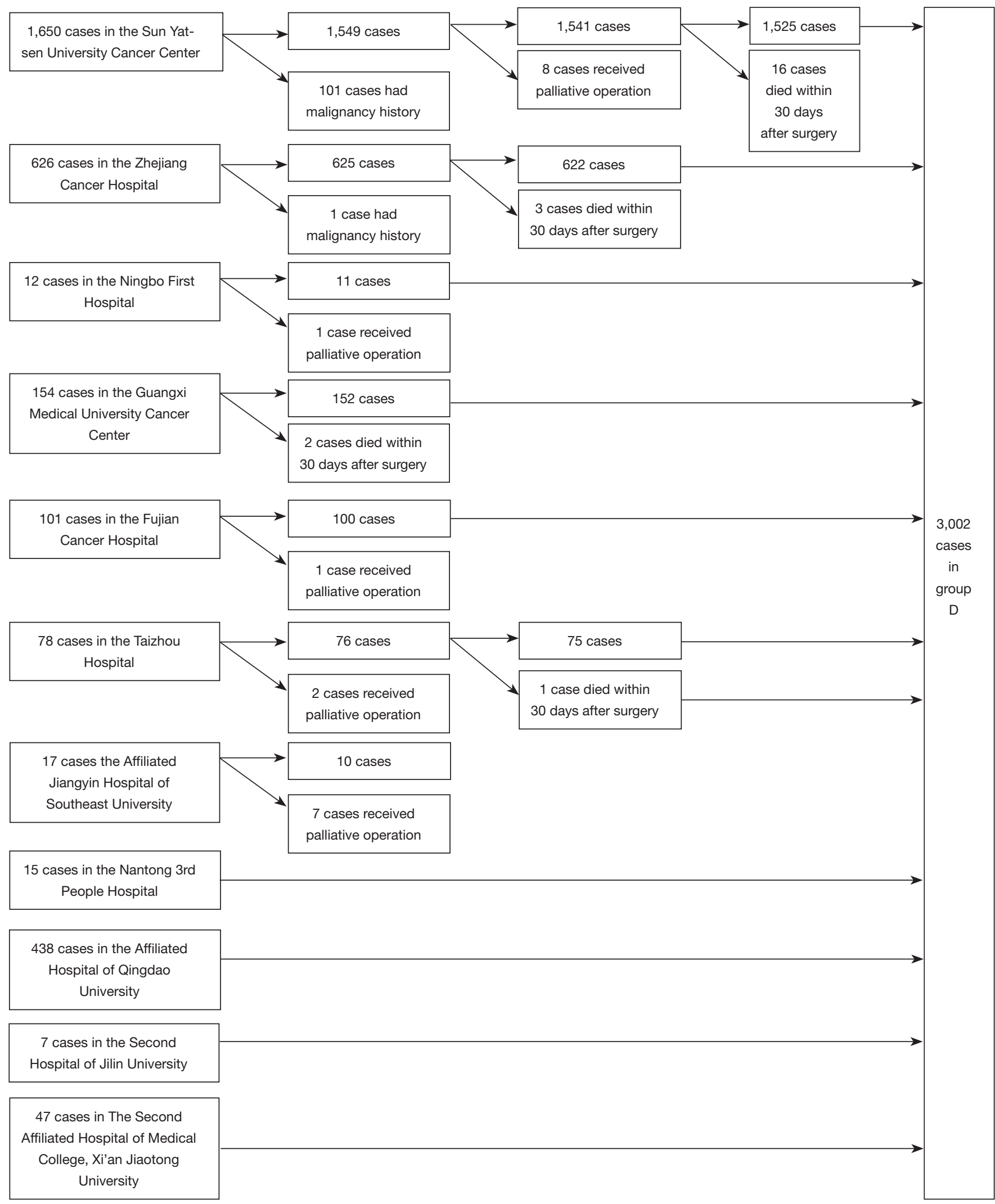

Figure 1 Flowchart of the study cohort selection process. 
squamous cell carcinoma (SCC), adenosquamous carcinoma (ASC), and other histological types accounted for, $27.9 \%$, $2.9 \%$, and $3.1 \%$, respectively (see Table 1 ).

\section{$L N$ dissection}

The 3,002 patients in this study underwent 50,849 LN dissections in total, with the average number of ELNs being $16.9 \pm 9.85$ and the median number of ELNs being 15 (IQR, 10-12). The condition of station 10, 11 and station 12, 13, 14 were examined further. For station 10, $11 \mathrm{LN}$ dissection, 2,087 patients $(69.52 \%)$ underwent dissection of station $10 \mathrm{LN}$ with an average number of 2.3 patients. Section 11 dissections included 1,919 patients $(63.92 \%)$, with an average number of 1.8 . Overall, 2,609 patients (86.81\%) underwent one dissection of station 10, 11 LN. Regarding station 12, 13, $14 \mathrm{LN}$ dissection, 1,461 patients (48.67\%) underwent dissection of station $12 \mathrm{LN}$ with an average number of $1.5,993$ patients (33.08\%) underwent dissection of station $13 \mathrm{LN}$ with an average number of 1.1 , and 71 patients $(2.37 \%)$ underwent dissection of station $14 \mathrm{LN}$ with 119 LNs dissected. Overall, 1,764 patients (58.76\%) underwent dissection of station 12, 13, 14. (See Figure S1 and Table S1).

\section{Dissection of station 10, $11 \mathrm{LN}$}

Based on the examination of station 10, $11 \mathrm{LN}$, cases in this study $(n=3,002)$ were divided into an unexamined group [A0 group, n=393 (13.09\%)] and an examined group with at least one examination of either station [A1 group, $n=2,609$ $(89.91 \%)]$. Confounding was addressed and adjusted for with regard to the following baseline information of the two groups: age $(\mathrm{P}=0.10)$, sex $(\mathrm{P}=0.795)$, $\mathrm{T}$ stage $(\mathrm{P}=0.314)$, and histological type $(\mathrm{P}=0.702)$, which displayed no statistical differences between the two groups (Table 1).

Kaplan-Meier survival analysis suggested that the examined group had a superior 5-year OS rate to the unexamined group ( $80 \%$ vs. $76 \%, \mathrm{P}=0.018$ ). Furthermore, the subgroup analysis of different $\mathrm{T}$ stages showed that examination of station 10,11 LN was only meaningful for T1 stage $(\mathrm{P}=0.012)$. Although variance in the curve was observed the T2 subgroup, statistical significance was not reached $(\mathrm{P}=0.244)$. No statistical significance was found in respect to the $\mathrm{T} 3$ subgroup $(\mathrm{P}=0.491)$ (Figure 2).

Univariate Cox analysis revealed that $\mathrm{T}$ stage, age, sex, and histological type were prognostic factors (Table 2). These factors were subsequently included in multivariate
Cox analysis, and the results showed that examining at least one station 10,11 LN was an independent prognostic factor (HR, 0.758; 95\% CI: 0.622-0.925; $\mathrm{P}=0.006$ ) (Table 3).

\section{Dissection of station 12-14 LN}

Based on the examination of station 12,13 , and $14 \mathrm{LN}$, the 3,002 cases in this study were divided into an unexamined group (B0 group) and an examined group with at least one examination of either station (B1 group). There were 1,238 $(41.24 \%)$ and $1,764(58.76 \%)$ in the B0 and B1 groups, respectively. For accuracy, the baseline information of the two groups was analyzed. The B0 and B1 groups displayed no statistical difference in age $(\mathrm{P}=0.824)$, sex $(\mathrm{P}=0.367)$, or histological type $(\mathrm{P}=0.076)$; however, $\mathrm{T}$ stage $(\mathrm{P}=0.032)$ showed maldistribution between the two groups (Table 1).

Kaplan-Meier survival analysis suggested that the B1 group had a higher 5-year OS rate than the B0 group (82\% vs. $77 \%, \mathrm{P}=0.008)$. Further subgroup analysis of different $\mathrm{T}$ stages showed that examination of station $12,13,14 \mathrm{LN}$ was only meaningful for patients with T1 stage NSCLC $(\mathrm{P}=0.015)$. Although variance in the curve was observed in the T2 $(\mathrm{P}=0.207)$ and $\mathrm{T} 3(\mathrm{P}=0.396)$ subgroups, statistical significance was not observed (Figure 2).

Univariate Cox analysis showed that $\mathrm{T}$ stage, age, sex, and histological type were also prognostic factors (Table 2). Subsequently, a multivariate Cox analysis including these factors was conducted, and the results showed that examining at least one station 12, 13, 14 was an independent prognostic factor (HR, 0.836; 95\% CI: $0.722-$ 0.968; $\mathrm{P}=0.017$ ) (Table 3).

\section{Influence of the HI standard on survival}

Based on the HI standard, the 3,002 cases in this study were divided into two groups: an unmatched group, which did not meet the HI standard (C0 group), and a matched group (C1 group), which met the HI standard. There were $1,733(57.73 \%)$ and $1,269(42.27 \%)$ cases in the C0 and $\mathrm{C} 1$ groups, respectively. For accuracy, the baseline information of the two groups was analyzed. The C0 and C1 groups showed no statistically significant difference in age $(\mathrm{P}=0.551)$, sex $(\mathrm{P}=0.658)$, or histological type $(\mathrm{P}=0.076)$, however, $\mathrm{T}$ stage $(\mathrm{P}=0.002)$ showed maldistribution between the two groups (Table 1).

Kaplan-Meier survival analysis suggested that the C1 group had a better 5-year survival rate than the $\mathrm{C} 0$ group (83\% vs. $77 \%, \mathrm{P}<0.001)$. Subgroup analysis of different $\mathrm{T}$ 


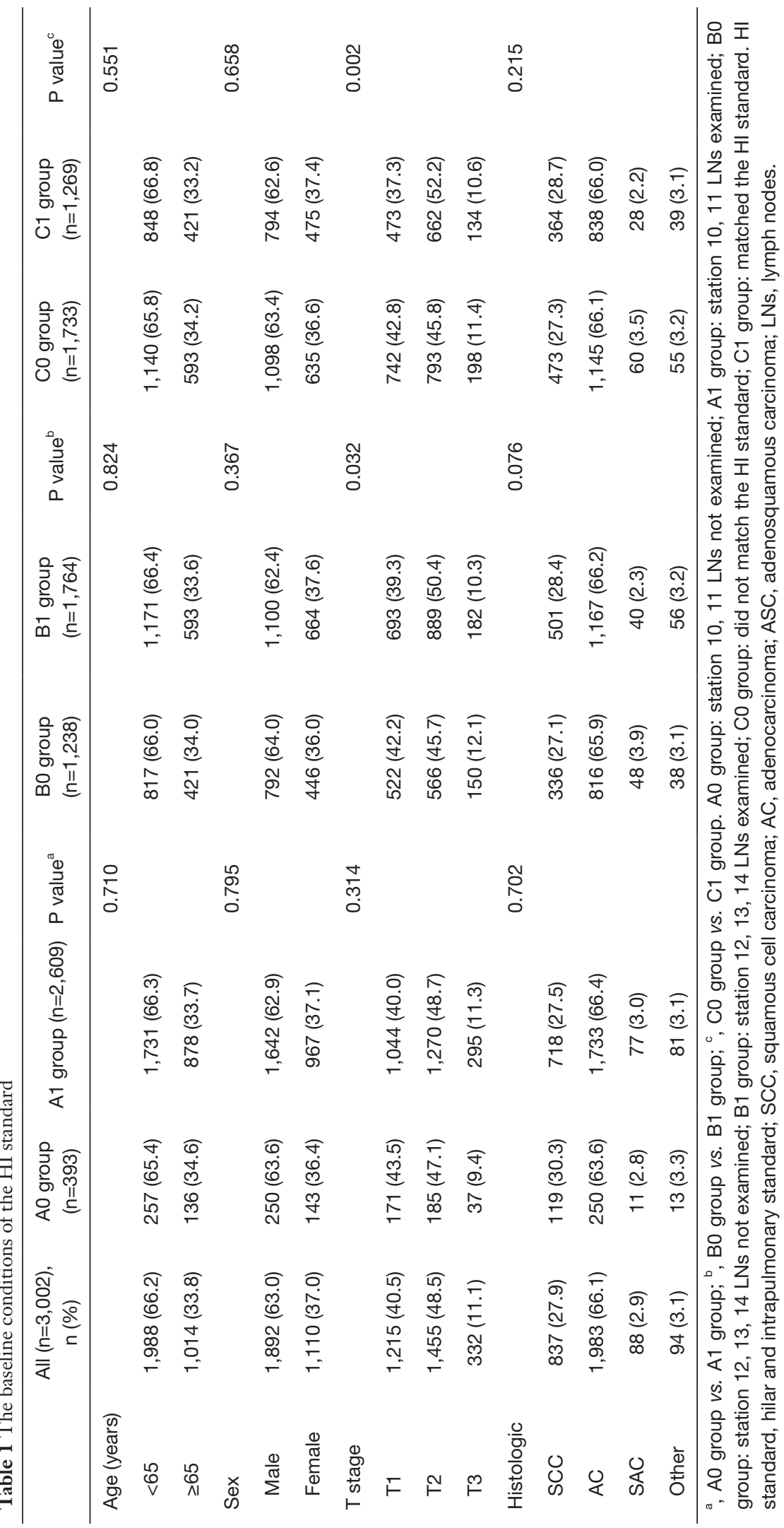



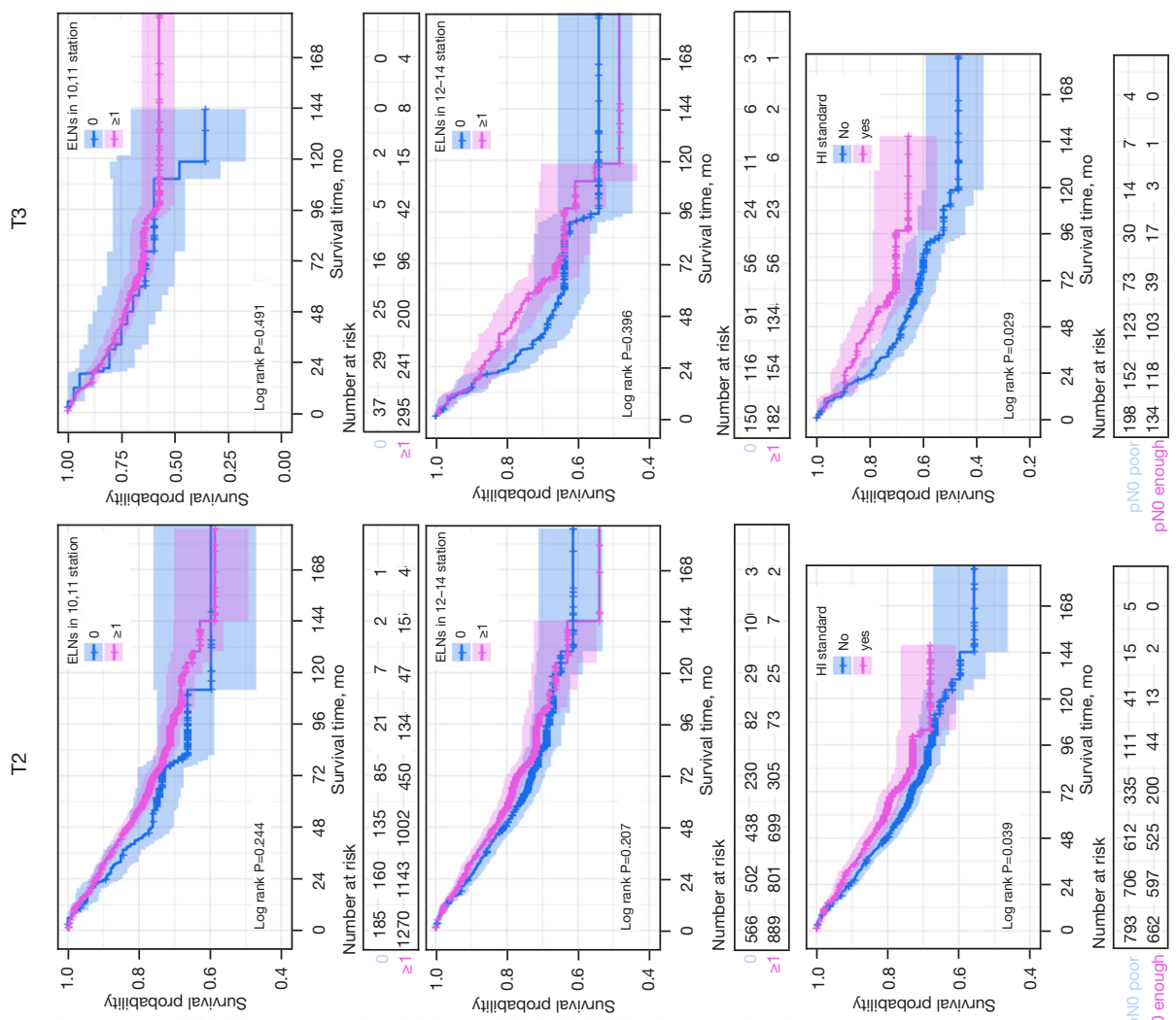

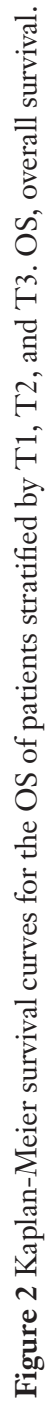




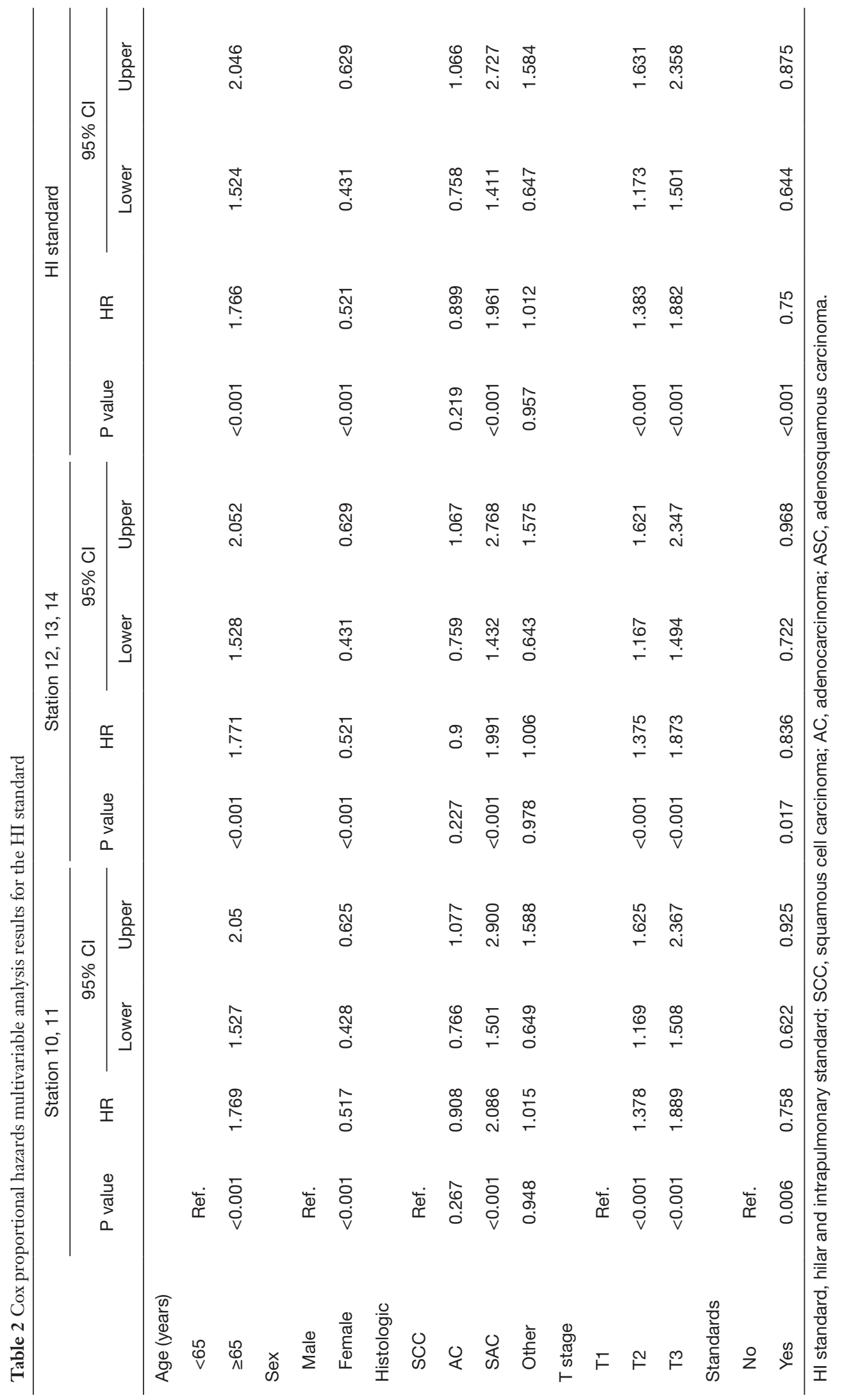




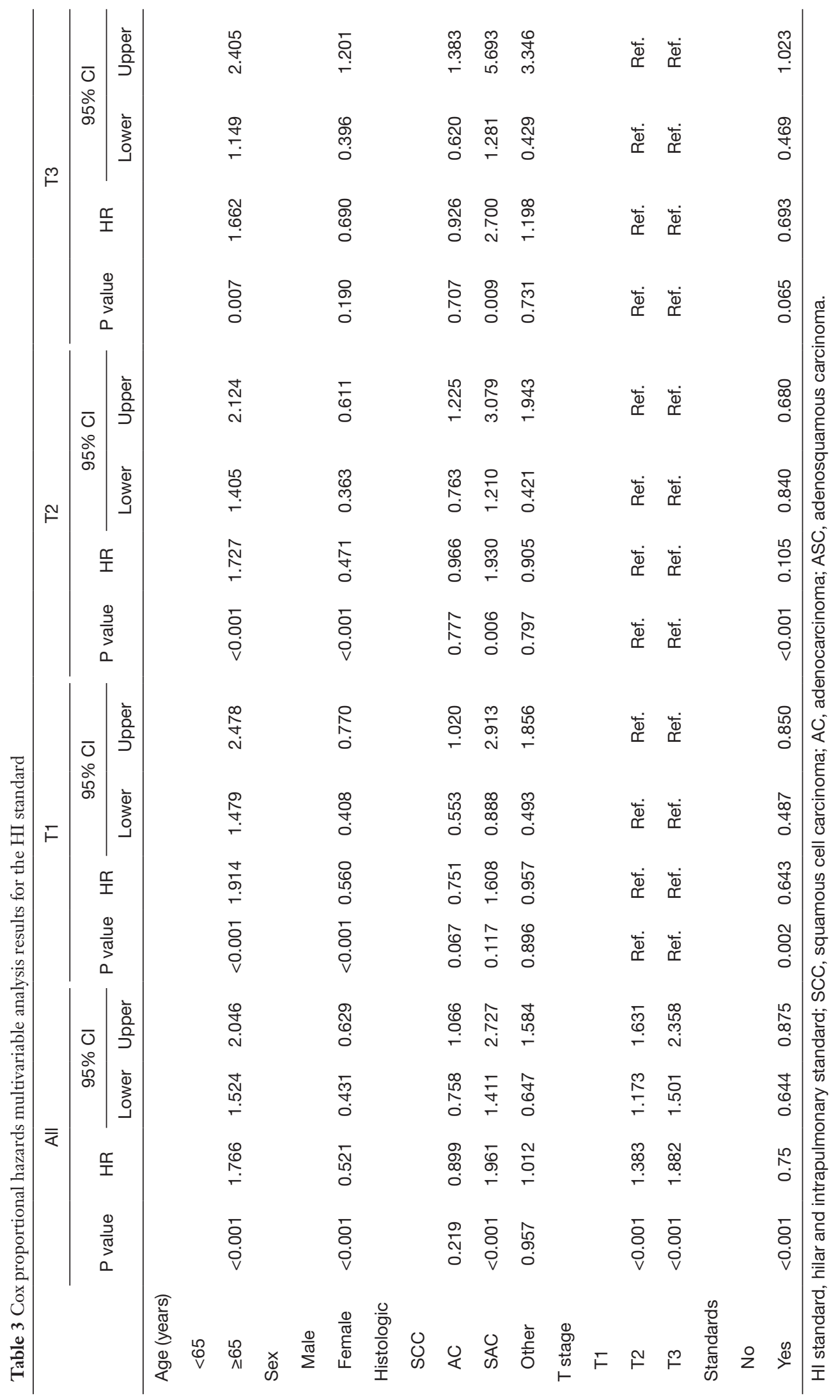


stages showed that the T1 $(\mathrm{P}=0.005), \mathrm{T} 2(\mathrm{P}=0.039)$, and T3 $(\mathrm{P}=0.029)$ subgroups all demonstrated statistical variances (Figure 2).

The univariate Cox analysis showed that $\mathrm{T}$ stage, age, sex, and histological type were prognostic factors (Table 2). Multivariate Cox analysis including these factors was subsequently performed, and the results showed that HI standard was an independent prognostic factor (HR, 0.750; 95\% CI: 0.644-0.875; $\mathrm{P}<0.001$ ) (Table 3).

\section{Discussion}

Sufficient intraoperative LN dissection is the foundation of surgery in NSCLC, aiding precise staging and prognostic prediction. Additionally, this provides guidance for postoperative adjuvant therapy and follow-up. Previous studies have revealed the importance of ELN number and N1 LN examination (23-25). However, current surgical guidelines mostly focus on mediastinal LNs, affording less attention to N1 LNs, especially intrapulmonary LNs. Moreover, the lack of a universal standard for $\mathrm{LN}$ dissection has led to confusion about radical excision among clinical surgeons, especially those in primary hospitals.

In this study, the dissection rates of station 10 and 11 LNs were $69.52 \%$ and $63.92 \%$, respectively. When judged by at least one dissection of station $10,11 \mathrm{LN}$, the general matching rate of the 11 centers was $86.9 \%$, with that of 10 centers being over $80 \%$. Allen et al.'s research showed similar results, with approximately $20 \%$ of patients not undergoing hilar or intrapulmonary LN dissection (12). Moreover, in this study, the average number of station10, $11 \mathrm{LNs}$ dissected was 4.1, which is similar to the results of Ramirez et al. (15). The dissection rates of station 12, 13, and $14 \mathrm{LNs}$ among the patients in this study were $48.67 \%$, $33.08 \%$, and $2.37 \%$, respectively. When judged by at least one dissection of station 12,13 and 14 LNs, the general matching rate of the 11 centers was only $58.8 \%$, with the rate being below $30 \%$ for more than half of the centers. The dissection rate of station $10,11 \mathrm{LN}$ was significantly higher than that of stations 12,13 and 14. This could be the result of specific regulations for hilar LNs by multiple guidelines, including NCCN, and unregulated station 12, 13, 14 LNs were easily ignored. Smeltzer $e t$ al.'s study reported that a second dissection revealed unexamined LNs in $90 \%$ of lung samples, with $12 \%$ of $\mathrm{N} 0$ patients having metastasis in abandoned LNs (19). Wang et al.'s study showed that almost $61 \%(n=435)$ of patients who did not undergo intrapulmonary LN examination had a significantly worse OS than those who did $(\mathrm{P}=0.027)(18)$, which indicates that the dissection and examination of LNs at station 12, 13, 14 could reduce false negative LNs and improve diagnostic precision.

The results of this study indicates that the examination of station 10,11 or station $12,13,14 \mathrm{LNs}$ is associated with increased patient survival rates. However, in further subgroup analysis, we found that this benefit only had statistical significance in T1 patients, and although variance was observed in the Kaplan-Meier survival curves of T2 and T3 patients, statistical significance not reached. Similarly, data from Asamura et al. (26) showed that the 5-year survival rates of patients with T1N0M0 and T1N1M0 NSCLC were $85 \%$ and $61 \%$, respectively, and that the survival differences between patients with N0 status and N1 status were more significant in the $\mathrm{T} 1$ group than in the $\mathrm{T} 2$ and T3 groups. Therefore, $\mathrm{N}$ status is more important to the prognosis of $\mathrm{T} 1$ patients than to that of $\mathrm{T} 2$ and $\mathrm{T} 3$ patients, which may explain why examination of only station 10,11 or only station $12,13,14 \mathrm{LNs}$ failed to display statistical significance. In addition, we found that the HI standard showed statistically significant survival rates in not only T1 patients, but also $\mathrm{T} 2$ and $\mathrm{T} 3$ patients, which indicates that the combination of LN number and location has superior OS to observing these factors individually.

Our study is the largest retrospective study to focus on the association of both the number and location of ELNs with T1-3N0M0 NSCLC patient survival. We first established a HI standard for early NSCLC based on a minimum of 10 ELNs, including at least one station 10, $11 \mathrm{LN}$ and one station 12, 13, $14 \mathrm{LN}$. Inadequate ELNs could potentially result in residual metastasized LNs, which might result increase the risk of recurrence. Unexamined and metastasized N1 LNs could potentially be missed, meaning the patient would not receive chemotherapy or strict surveillance programs following treatment, resulting in a worse prognosis. According to the above discussion, many N1 LNs did not undergo further dissection and examination, which suggests that stringent requirements on N1 LN dissection would not increase the surgical difficulty or the risk of complications. In clinical practice, further dissection of N1 LNs only takes about 10 minutes but contributes to better staging and prognosis. Therefore, it is crucial that more attention is given to not only the number but also the location of ELNs.

There are certain limitations to this study as a result of 
the retrospective design. Firstly, LN counting might be imprecise or vary in clinical practice. For instance, during surgery, multiple LNs could be dissected together due to adhesion and ultimately be counted as a single $\mathrm{LN}$. On the other hand, during surgery, one LN might also be divided into many fragments and counted as multiple LNs. However, these factors had little impact on our study. Although the adhesion and fragmentation of LNs are commonly seen in patients with advanced disease, this study focused mainly on T1-3N0M0 NSCLC; and a morerare form of the disease. Furthermore, the collected data were all obtained from real-world practices, which suggests that the results are close to the real-world situation with a large sample size. Our next multicenter and multinational prospective study will further evaluate the efficacy of the $\mathrm{HI}$ standard.

The updated HI standard provides important guidance for pulmonary LN dissection and pathological examination in patients with T1-3N0M0 NSCLC. For such patients, a minimum of 10 ELNs, including at least one LN from station 10, 11 and one $\mathrm{LN}$ from station 12,13,14, is recommended in order to obtain the optimal survival benefit.

\section{Acknowledgments}

The authors appreciate the academic support from the AME Lung Cancer Collaborative Group. We sincerely express our gratitude to Hui Zhu for providing language support.

Funding: This study was supported by the Science and Technology Planning Project of Guangdong Province, China (2017A020219009); National Natural Science Foundation of China (81760478); and the Breeding Program for Junior Teachers in Sun Yat-sen University (KY051083).

\section{Footnote}

Reporting Checklist: The authors have completed the STROBE reporting checklist. Available at https://dx.doi. org/10.21037/tlcr-21-959

Data Sharing Statement: Available at https://dx.doi. org/10.21037/tlcr-21-959

Conflicts of Interest: All authors have completed the ICMJE uniform disclosure form (available at https://dx.doi. org/10.21037/tlcr-21-959). Dr. NRV reports that he had received compensation for participation in research studies and advisory meetings from AstraZeneca, PRC Corporation, Medtronic, MJH Life Sciences, Trevena, Intuitive, Endogastric Solutions, Ethicon and sponsored travel all for educational activities. The other authors have no conflicts of interest to declare.

Ethical Statement: The authors are accountable for all aspects of the work in ensuring that questions related to the accuracy or integrity of any part of the work are appropriately investigated and resolved. The study was conducted in accordance with the Declaration of Helsinki (as revised in 2013). The study was approved by the committee board of Sun Yat-sen University Cancer Center (No. YB2018-11), and individual consent for this retrospective analysis was waived.

Open Access Statement: This is an Open Access article distributed in accordance with the Creative Commons Attribution-NonCommercial-NoDerivs 4.0 International License (CC BY-NC-ND 4.0), which permits the noncommercial replication and distribution of the article with the strict proviso that no changes or edits are made and the original work is properly cited (including links to both the formal publication through the relevant DOI and the license). See: https://creativecommons.org/licenses/by-nc-nd/4.0/.

\section{References}

1. Silvestri GA, Gonzalez AV, Jantz MA, et al. Methods for staging non-small cell lung cancer: Diagnosis and management of lung cancer, 3 rd ed: American College of Chest Physicians evidence-based clinical practice guidelines. Chest 2013;143:e211S-e250S.

2. Osarogiagbon RU, Allen JW, Farooq A, et al. Pathologic lymph node staging practice and stage-predicted survival after resection of lung cancer. Ann Thorac Surg 2011;91:1486-92.

3. Liu S, Zhou F, Liu Z, et al. Predictive and prognostic significance of $M$ descriptors of the 8 th TNM classification for advanced NSCLC patients treated with immune checkpoint inhibitors. Transl Lung Cancer Res 2020;9:1053-66.

4. D'Cunha J, Herndon JE 2nd, Herzan DL, et al. Poor correspondence between clinical and pathologic staging in 
stage 1 non-small cell lung cancer: results from CALGB 9761, a prospective trial. Lung Cancer 2005;48:241-6.

5. National Comprehensive Cancer Network. NCCN clinical practice guidelines in oncology: non-small cell lung cancer. Version 1. 2019. Available online: https:// www.nccn.org/professionals/physician_gls/pdf/nscl.pdf

6. De Leyn P, Dooms C, Kuzdzal J, et al. Revised ESTS guidelines for preoperative mediastinal lymph node staging for non-small-cell lung cancer. Eur J Cardiothorac Surg 2014;45:787-98.

7. Brunelli A, Charloux A, Bolliger CT, et al. ERS/ESTS clinical guidelines on fitness for radical therapy in lung cancer patients (surgery and chemo-radiotherapy). Eur Respir J 2009;34:17-41.

8. Chinese Medical Association; Oncology Society of Chinese Medical Association; Chinese Medical Association Publishing House. Chinese Medical Association guidelines for clinical diagnosis and treatment of lung cancer (Edition 2018). Zhonghua Zhong Liu Za Zhi 2018;40:935-64.

9. American College of Surgeons. CoC Quality of Care Measures. CoC Measures for Quality of Cancer Care. Available online: https://www.facs.org/quality\%20 programs/cancer/ncdb/qualitymeasures (Posted Fall 2014; Accessed August 20, 2017).

10. Samayoa AX, Pezzi TA, Pezzi CM, et al. Rationale for a Minimum Number of Lymph Nodes Removed with Non-Small Cell Lung Cancer Resection: Correlating the Number of Nodes Removed with Survival in 98,970 Patients. Ann Surg Oncol 2016;23:1005-11.

11. Zhu Z, Song Z, Jiao W, et al. A large real-world cohort study of examined lymph node standards for adequate nodal staging in early non-small cell lung cancer. Transl Lung Cancer Res 2021;10:815-25.

12. Allen JW, Farooq A, O'Brien TF, et al. Quality of surgical resection for nonsmall cell lung cancer in a US metropolitan area. Cancer 2011;117:134-42.

13. Osarogiagbon RU, Decker PA, Ballman K, et al. Survival Implications of Variation in the Thoroughness of Pathologic Lymph Node Examination in American College of Surgeons Oncology Group Z0030 (Alliance). Ann Thorac Surg 2016;102:363-9.

14. Smeltzer MP, Faris NR, Ray MA, et al. Association of Pathologic Nodal Staging Quality With Survival Among Patients With Non-Small Cell Lung Cancer After Resection With Curative Intent. JAMA Oncol 2018;4:80-7.
15. Ramirez RA, Wang CG, Miller LE, et al. Incomplete intrapulmonary lymph node retrieval after routine pathologic examination of resected lung cancer. J Clin Oncol 2012;30:2823-8.

16. Osarogiagbon RU, Eke R, Sareen S, et al. The impact of a novel lung gross dissection protocol on intrapulmonary lymph node retrieval from lung cancer resection specimens. Ann Diagn Pathol 2014;18:220-6.

17. Ray MA, Faris NR, Smeltzer MP, et al. Effectiveness of Implemented Interventions on Pathologic Nodal Staging of Non-Small Cell Lung Cancer. Ann Thorac Surg 2018;106:228-34.

18. Wang X, Yan S, Lv C, et al. Impact of Omission of Intrapulmonary Lymph Node Retrieval on Outcome Evaluation of Lung Cancer Patients Without Lymph Node Metastasis: A Propensity Score Matching Analysis. Clin Lung Cancer 2017;18:e411-6.

19. Smeltzer MP, Faris N, Yu X, et al. Missed Intrapulmonary Lymph Node Metastasis and Survival After Resection of Non-Small Cell Lung Cancer. Ann Thorac Surg 2016;102:448-53.

20. Samson P, Crabtree T, Broderick S, et al. Quality Measures in Clinical Stage I Non-Small Cell Lung Cancer: Improved Performance Is Associated With Improved Survival. Ann Thorac Surg 2017;103:303-11.

21. Association of Directors of Anatomic and Surgical Pathology. Recommendations for processing and reporting of lymph node specimens submitted for evaluation of metastatic disease. Am J Clin Pathol 2001;115:799-801.

22. Rusch VW, Asamura H, Watanabe H, et al. The IASLC lung cancer staging project: a proposal for a new international lymph node map in the forthcoming seventh edition of the TNM classification for lung cancer. J Thorac Oncol 2009;4:568-77.

23. Zhai $W$, Duan F, Zheng Y, et al. Significance of accurate hilar and intrapulmonary lymph node examination and prognostication in stage IA-IIA non-small cell lung cancer, a retrospective cohort study. World J Surg Oncol 2020;18:258.

24. Wang G, Wu X, Sun X, et al. Value of N1 Lymph Node Examination in the Prognosis of Patients With pT13N0M0 Non-Small Cell Lung Cancer. Front Oncol 2020;10:603378.

25. Maeshima AM, Tsuta K, Asamura H, et al. Prognostic implication of metastasis limited to segmental (level 13) and/or subsegmental (level 14) lymph nodes in patients with surgically resected nonsmall cell lung carcinoma 
and pathologic N1 lymph node status. Cancer 2012;118:4512-8.

26. Asamura H, Chansky K, Crowley J, et al. The International Association for the Study of Lung Cancer
Lung Cancer Staging Project: Proposals for the Revision of the N Descriptors in the Forthcoming 8th Edition of the TNM Classification for Lung Cancer. J Thorac Oncol 2015;10:1675-84.

Cite this article as: Zhu Z, Mei W, Song Z, Jiao W, Huang Q, Zhu L, An C, Shi J, Wang W, Yu G, Sun P, Zhang Y, Shen J, Song Y, Gilbert S, Ruetzler K, Villamizar NR, Xu C, Qian J, Yao W, Yang H; written on behalf of AME Lung Cancer Collaborative Group. A standard for hilar and intrapulmonary lymph node dissection and pathological examination in early non-small cell lung cancer. Transl Lung Cancer Res 2021;10(12):4587-4599. doi: 10.21037/tlcr-21-959 
Box-plot

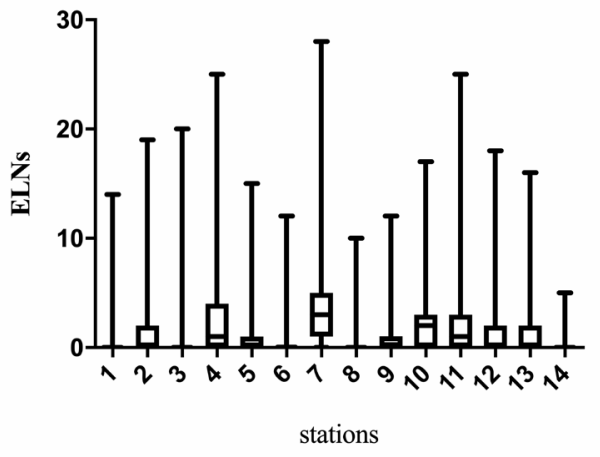

Violin Plot

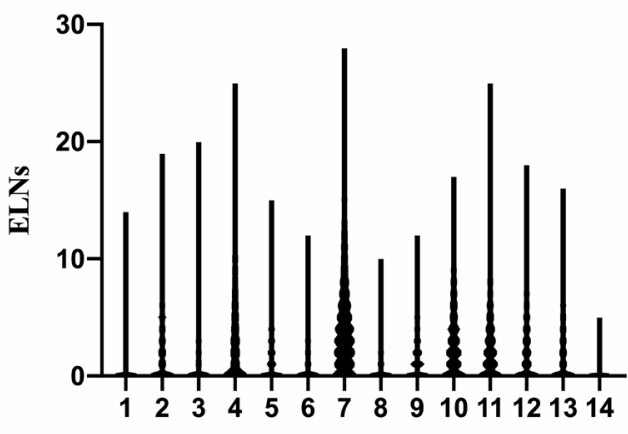

stations

Figure S1 Box-plot and violin plot for the number of ELNs at each station. ELNs, examined lymph nodes.

Table S1 The examination of each station

\begin{tabular}{|c|c|c|c|c|c|}
\hline Station & Sum & Average & SD & No. of cases with ELNs & $\begin{array}{c}\text { Percentage of cases with } \\
\text { ELNs }(\%)\end{array}$ \\
\hline 1 & 285 & 0.1 & 0.66 & 98 & 3.26 \\
\hline 3 & 1,043 & 0.3 & 1.17 & 387 & 12.89 \\
\hline 4 & 7,431 & 2.5 & 3.42 & 1,689 & 56.26 \\
\hline 6 & 1,097 & 0.4 & 1.17 & 416 & 13.86 \\
\hline 7 & 11,274 & 3.8 & 3.51 & 2,516 & 83.81 \\
\hline 8 & 627 & 0.2 & 0.75 & 334 & 11.13 \\
\hline 12 & 4,567 & 1.5 & 2.25 & 1,461 & 48.67 \\
\hline 13 & 3,222 & 1.1 & 2.11 & 993 & 33.08 \\
\hline 14 & 119 & 0.0 & 0.29 & 71 & 2.37 \\
\hline
\end{tabular}

SD, standard deviation; ELNs, examined lymph nodes. 